\title{
An analytical model of homogeneous charge compression ignition engine for performance prediction
}

\begin{abstract}
A zero dimensional thermodynamic model simulation is developed to simulate the combustion characteristics and performance of a four stroke homogeneous compression combustion ignition (HCCI) engine fueled with gasoline. This model which applies the first law of thermodynamics for a closed system is inclusive of empirical model for predicting the important parameters for engine cycles: the combustion timing and mass burnt fraction during the combustion process. The hypothesis is the increasing intake temperature can reduce the combustion duration and the fuel consumption at wide range of equivalence ratio. The intake temperature were increased from $373-433 \mathrm{~K}$ with increment of $20 \mathrm{~K}$. The engine was operated over a range of equivalence ratios of 0.2 to 0.5 at constant engine speed of 1200 rpm and intake pressure of 89,950 k Pa. Simulations were performed using Simulink ${ }^{\circledR}$ under different engine operating conditions. Increasing intake temperature allows reducing the combustion duration by $0.99{ }^{\circ} \mathrm{CA}$ and $0.26{ }^{\circ} \mathrm{CA}$ at equivalence ratios of 0.2 and 0.5 , respectively. The brake specific fuel consumption decreases about 6.09\%-5.76\% at 0.2-0.5 of equivalence ratios. Thus, fuel consumption can be reduced by increasing intake temperature.
\end{abstract}

Keyword: HCCI; Intake temperature; Equivalence ratio; Combustion duration; Computer programming; Simulink 